
allemande

$52-2 \mid 2020$

Les traités de paix en Europe centrale : quels potentiels pour quelles réalisations?

\title{
Bernd WEGNER, Das deutsche Paris. Der Blick der Besatzer 1940-1944
}

Paderborn, Schoeningh, 2019

\section{Gilles Buscot}

\section{(2) OpenEdition}

Édition électronique

URL : https://journals.openedition.org/allemagne/2500

DOI : 10.4000 /allemagne. 2500

ISSN : 2605-7913

\section{Éditeur}

Société d'études allemandes

Édition imprimée

Date de publication : 31 décembre 2020

Pagination : 445-446

ISSN : 0035-0974

Référence électronique

Gilles Buscot, "Bernd wegner, Das deutsche Paris. Der Blick der Besatzer 1940-1944 », Revue d'Allemagne et des pays de langue allemande [En ligne], 52-2 I 2020, mis en ligne le 31 décembre 2020, consulté le 20 février 2022. URL : http://journals.openedition.org/allemagne/2500 ; DOI : https://doi.org/10.4000/ allemagne. 2500 
de l'activité laborieuse (Arbeitsamkeit) subsiste, mais, avec l'industrialisation, la fierté de l'artisan pour le bel objet est remplacée par le culte de la productivité et le souci de

la compétitivité. Le salariat se développe et gagne le monde de la bourgeoisie.

La consommation cesse d'être simplement la contrepartie passive de la production: elle devient une forme d'activité destinée à équilibrer le travail, comme le préconisent les préceptes d'hygiène diffusés à la fin du XIXe siècle. Le congé d'été devient un élément important du calendrier chez les gens aisés. Si le luxe est toujours - au moins dans la rhétorique - condamné, les distractions ne sont nullement réprouvées, même quand elles se déroulent hors du cadre familial. Dans les journaux personnels, le théâtre, le sport, la mode, les voyages touristiques en Italie et le cinéma prennent une place croissante. La consommation est perçue de plus en plus comme une grandeur fondamentale dans les calculs des économistes. La question essentielle n'est plus de modérer les appétits selon la morale traditionnelle mais de faire en sorte que l'argent dépensé nourrisse l'économie nationale. Les sciences sociales introduisent le concept de niveau de vie.

L'auteur note que toutes ces évolutions ne débouchent pas encore pour autant sur l'individualisme postmoderne: si le modèle très contraignant de la famille souche a cédé la place à celui, plus libéral, de la famille nucléaire, cette dernière apparaît à l'ensemble des diaristes de la période comme le centre de la vie quotidienne et le but à atteindre. Parmi les critères de réussite s'ajoute même la transmission aux héritiers d'un patrimoine. Une comparaison avec les espaces situés hors du monde germanophone montrerait peut-être que cette orientation reste plus nette dans l'Europe rhénane que, par exemple, dans le monde anglo-saxon. Mais cela reste à vérifier à partir du même type de source et selon les mêmes méthodes.

Michel Hau

Bernd WEGNER, Das deutsche Paris. Der Blick der Besatzer 1940-1944, Paderborn, Schoeningh, 2019, $259 p$.

Der Blick der Besatzer, ouvrage écrit par l'historien Bernd Wegner, richement illustré par des documents authentiques, frappe dès l'abord par son originalité. À commencer par celle de l'objet d'étude: l'occupation allemande de la capitale durant la Seconde Guerre mondiale a été certes souvent analysée du point de vue du Paris occupé, mais beaucoup moins de celui de l'occupant. Originalité de la démarche, ensuite: s'appuyant tout à la fois sur un nombre impressionnant de lettres, de témoignages individuels, de directives, d'affiches et de photographies publiques ou privées, Bernd Wegner parvient très concrètement à nous replonger dans l'ambiance si particulière et paradoxale des années d'occupation, mêlant une approche chronologique et thématique de son sujet. Le lecteur assiste, pas à pas, à l'évolution de la situation au fil des semaines, des mois et des années, ce qui n'empêche pas l'auteur d'établir de constants parallèles (on serait tenté de dire des va-et-vient) entre les différentes phases de l'occupation allemande.

Ces périodes successives s'éclairent ainsi mutuellement: l'attentisme français de la période qui précéda immédiatement l'arrivée des armées allemandes; la désertion, dans un premier temps, par les Parisiens aisés; puis l'arrivée des troupes allemandes et un certain soulagement, de part et d'autre, en constatant qu'un redémarrage de la vie économique et sociale était possible; dès lors une forme de sidération allemande 
face à une capitale à la fois impuissante, vivante et mythique; un mélange de fierté du vainqueur, d'admiration, parfois de commisération et de curiosité pour la villelumière; un tourisme culturel pour lequel Hitler lui-même avait donné le ton lors de son séjour à Paris - ou au contraire, chez certains, une prise de distance critique et un repli identitaire; une volonté de se poser en "civilisateur", voire en protecteur face à la peur des Rouges et du danger venu de l'ennemi russe; une envie, chez d'autres soldats allemands, de profiter de la vie et des plaisirs faciles, plus ou moins illicites; de commercer, à tous les sens du terme, avec les Parisiens et les Parisiennes, entre autres pour les plaisirs de l'esprit ou de la chair; d'acquérir des articles à la mode ou bien de véritables œuvres d'art, souvent à vil prix; puis les tensions montantes à mesure que l'Allemagne perd du terrain, les attentats et les terribles représailles "pour l'exemple»; enfin la libération de Paris et des scènes de vengeances vécues par les soldats allemands comme l'humiliation suprême; la tentation, chez quelques-uns, de pactiser avec le vainqueur; le regret, chez d'autres, de s'être montrés "trop humains" durant l'occupation; jusqu'à la menace, évitée de justesse, d'un anéantissement total de Paris. À propos de toutes ces phases, Bernd Wegner n'est jamais caricatural. Il s'appuie sur un nombre si impressionnant de lettres et de témoignages (y compris celles de grands intellectuels) que ses exemples et contre-exemples lui permettent toujours de dégager la véritable pluralité et complexité des regards allemands portés sur Paris. Vers la fin de l'ouvrage, Bernard Wegner établit même une typologie récapitulative, claire et convaincante: l'occupant allemand fut tantôt un provincial nationaliste, peu enclin à découvrir Paris, tantôt un "touriste de guerre» curieux et étonné, parfois un aventurier à la recherche de sensations fortes, parfois encore un bourgeois cultivé, avide de contacts avec les intellectuels et les artistes français, souvent un simple flâneur... Parfois, paradoxalement, il endosse alternativement toutes ces postures... Sans compter d'autres attitudes plus singulières: certains soldats allemands affectés à Paris cherchèrent à pactiser avec l'habitant, d'autres se sentirent mal à l'aise dans leur uniforme militaire. Beaucoup furent enviés par leurs compatriotes qui combattaient sur d'autres fronts, souvent dénigrés par le régime nazi et certains civils qui voyaient en ces «Parisiens allemands» des privilégiés affadis et des profiteurs éhontés...

Autre originalité de l'ouvrage, Bernd Wegner choisit, pour chacun de ses titres, des citations marquantes extraites de lettres ou de témoignages qu'il va ensuite passer au crible (incluant même, au passage, le titre d'une célèbre chanson française de l'époque!). Ces formulations ciselées et ce matériau brut saisissent instantanément l'esprit du temps, conférant à la lecture un caractère vivant et captivant. Et pour donner plus d'épaisseur encore à son regard d'historien, Bernd Wegner insère sous ses titres des citations-épigraphes plus longues, issues notamment de deux autres époques-charnières où la ville de Paris fut également occupée par des soldats allemands: 1814-1815 et 1870-1871, deux périodes marquant respectivement la fin du Premier et du Second Empire. Contextes très différents de celui de la Seconde Guerre mondiale, certes, mais il est frappant de constater a posteriori que la réalité ressentie et les clichés furent parfois très ressemblants d'un siècle à l'autre. De fait, Paris était tout sauf une page blanche dans la mémoire et l'imaginaire collectifs allemands...

Ajoutons enfin que Der Blick der Besatzer est rédigé dans une langue élégante qui concilie précision, goût de la nuance et clarté de l'exposé. De fait, ce livre novateur, véritable travail de bénédictin, dépoussière mainte idée reçue. II se lit tout à la fois comme un ouvrage scientifique de premier plan et comme une cuvre littéraire vivante et palpitante, parfaitement accessible au grand public. 